\title{
A REESCRITA COMO PROCESSO: AS VANTAGENS DE UMA SEGUNDA VERSÃO TARDIA
}

\author{
Adriane Teresinha SARTORI ${ }^{1}$ \\ Lucíola Zacarias MENDES ${ }^{2}$
}

\begin{abstract}
Resumo: Este trabalho analisa duas versões de textos produzidos por alunos de Educação de Jovens e Adultos de Ensino Médio de uma escola pública de Belo Horizonte, confirmando a reescrita como etapa fundamental do processo de escrita e discutindo as vantagens de uma segunda versão tardia, propiciando mudanças significativas nas primeiras versões entregues. Os textos produzidos fazem parte de uma experiência realizada no âmbito de uma pesquisa-ação (THIOLLENT, 2007), desenvolvida numa relação colaborativa entre escola pública e instituição de ensino superior. A análise, de natureza qualitativa e embasada na concepção de dialogismo do Círculo de Bakhtin (1986, 2003), focaliza especialmente os aspectos temáticos dos textos, procurando desvelar a articulação de vozes realizada pelos alunos. Os resultados positivos da experiência parecem comprovar a importância de um intervalo significativo entre a produção das versões de um mesmo texto, visando dar tempo ao autor para apropriar-se de novos/outros conhecimentos.
\end{abstract}

Palavras-chave: Escrita. Reescrita. Intervalo de tempo. Dialogismo.

\section{Introdução}

O ensino de língua portuguesa está em discussão desde os anos 1980. Já é consenso entre os especialistas que o livro $O$ texto na sala de aula ${ }^{3}$ é um marco de propostas inovadoras para o ensino de língua e literatura em resposta à necessária

\footnotetext{
${ }^{1}$ UFMG - Universidade Federal de Minas Gerais. Belo Horizonte - Minas Gerais - Brasil. 31270-901. adriane.sartori@gmail.com

${ }^{2}$ UFMG - Universidade Federal de Minas Gerais - Rede estadual de ensino. Belo Horizonte - Minas Gerais - Brasil. 30535-570. luciolamletras@gmail.com

${ }^{3}$ A publicação de "O texto na sala de aula: um clássico sobre ensino de língua portuguesa", organizado por Silva, Almeida Ferreira e Mortatti (2014), comprova essa afirmativa.
}

http://dx.doi.org/10.21165/gel.v13i3.1462 
substituição das tradicionais aulas de gramática. O ensino deveria voltar-se, então, às práticas de leitura, de escrita e de análise linguística (GERALDI, 1984).

Em relação à escrita, denunciando a existência de textos elaborados para a escola, as chamadas "redações", Geraldi (1984), nessa mesma obra, propõe a reescrita como parte essencial do trabalho, já que cabe ao professor apresentar a análise linguística partindo do texto "com problemas" para auxiliar o aluno a reescrevê-lo (GERALDI, 2002, p. 74).

Estando essas ideias em voga desde os anos 1980, podemos nos perguntar por qual motivo o trabalho com a reescrita não se efetiva em grande parte das escolas brasileiras. A resposta não é simples, porque complexa é a análise de todo o sistema educacional brasileiro. Mas, buscando minimamente algumas possibilidades de respostas, podemos dizer que:

a) a divisão da disciplina de Língua Portuguesa em redação, gramática e literatura, em boa parte das escolas, impede um trabalho mais processual nas aulas de produção de texto;

b) a partição do trabalho entre dois ou mais profissionais, quando um professor solicita a redação e um monitor, por exemplo, faz a correção do texto, também cria obstáculos para um acompanhamento do processo de escrita do aluno;

c) a programação da série, baseada em conteúdos estanques, impossibilita um trabalho reflexivo;

d) a concepção de reescrita como "passar a limpo", atividade que geralmente o aluno realiza como tarefa extraescolar e atende à necessidade de "higienização" do texto (GERALDI, 1984; JESUS, 1997).

Como dissemos, esses fatores, entre tantos outros, podem ser os responsáveis pela inexistência de reescrita na escola, ou pelo trabalho inexpressivo nessa área, um problema significativo das aulas de língua portuguesa, que precisa ser revisto, para que possamos construir práticas alternativas, visando ensinar a escrever.

Partindo do pressuposto de que reescrever é etapa indispensável do processo de escrita e considerando as inúmeras dificuldades que os alunos da educação básica apresentam quanto a produzir um texto escrito que atinja seus propósitos em determinado contexto de circulação, este artigo relata uma experiência realizada com a prática de produção de textos, em 2013, em uma escola pública de Ensino Médio, em 
Belo Horizonte, inserida em um Projeto de Extensão denominado "Professor Universitário, Professor da Educação Básica, Aluno de Graduação e de Escola: um Encontro Necessário".

O Projeto objetiva identificar as dificuldades dos alunos do Ensino Médio quanto à leitura e à escrita e, a partir dessa identificação, construir, em equipe professor universitário, alunos de licenciatura em Letras, professor da educação básica -, alternativas para superá-las. As autoras deste artigo são integrantes desse Projeto, e uma delas foi a professora da turma na qual a experiência foi realizada.

Conforme configura-se a investigação, podemos dizer que se trata de uma pesquisa-ação (THIOLLENT, 1986). Essa abordagem filia-se a propostas de caráter qualitativo em educação (LÜDKE; ANDRÉ, 1986), e, neste caso, está guiada pelo olhar da Linguística Aplicada, tendo pressupostos bakhtinianos como sustentação, especialmente quanto aos fundamentos de sua concepção de dialogismo, destacando a articulação de vozes organizada pelo sujeito autor no seu texto.

Apresentamos, neste artigo, textos de dois alunos do Ensino Médio e suas respectivas reescritas. Entre a primeira e a segunda versão, oito meses se passaram, de forma que os alunos puderam reescrever com outros/novos conhecimentos, construídos em interação com o professor de Português, especialmente. Nesse sentido, tentaremos mostrar as vantagens de propor a reescrita tardia, ou seja, uma reescrita realizada com um intervalo de tempo significativo entre as duas versões. Consideramos que essa etapa pode ser "adiada", afinal, "[...] por mais ingênuo que possa parecer, para se produzir um texto é preciso que se tenha o que dizer [...]" (GERALDI, 1997, p. 137). Dessa forma, a proposta de reescrita tardia advém do pressuposto que "conhecimento de mundo" é fruto de um processo complexo de aprendizagem, envolvendo experiências de diversas ordens com/no mundo em que vivemos, não uma "transferência" de informações entre sujeitos.

É também nossa intenção, com este trabalho, preencher uma lacuna nos estudos sobre reescrita, visto que normalmente as pesquisas avaliam os efeitos de uma segunda versão imediatamente - ou com pouco intervalo de tempo - após a primeira versão. Na literatura pesquisada, não encontramos um estudo semelhante ao nosso.

Dessa forma, inicialmente, teceremos algumas considerações sobre o processo de escrita/reescrita para, na sequência, trazermos ideias do Círculo de Bakhtin (1986, 
2003). Em seguida, faremos a análise dos textos dos alunos, tendo o conteúdo temático como foco de atenção, para, então, tecermos as considerações finais.

\section{Situando a discussão: algumas considerações sobre (re)escrita}

Fiad e Mayrink-Sabinson (1991) tratam de questões importantes realizadas sobre esse eixo de ensino a partir dos anos 1980 em nosso país, tendo o grupo de estudiosos da Universidade Estadual de Campinas (UNICAMP) - entre eles, o professor Geraldi, supracitado - como fundadores. O objetivo básico desse grupo é construir práticas diferenciadas de escrita, já que na escola deveriam ser escritos textos não mais como comprovação das regras aprendidas nas aulas de gramática.

Assim, assumindo que a linguagem é construída por sujeitos em interação, Fiad e Mayrink-Sabinson (1991, p. 55) defendem que “[...] na modalidade escrita da linguagem, essa construção envolve momentos diferentes, como o de planejamento de um texto, o da própria escrita do texto, o da leitura do texto pelo próprio autor, o das modificações feitas no texto a partir dessa leitura." (p. 55). A etapa de reescrita, na concepção de escrita como trabalho, é primordial, é constitutiva do processo, de tal forma que, para as autoras, o ensino da escrita é uma "aprendizagem do trabalho de reescritas" (p. 55).

Fiad e Mayrink-Sabinson (1991) perguntam-se: quando reescrevem, que mudanças fazem os alunos? A análise de 40 textos de calouros da UNICAMP, cursando a disciplina Prática de Leitura e Produção de Textos, revela o seguinte:

[...] em primeiro lugar, as mudanças são uma resposta a alguma observação feita pelo leitor (professor ou colega) ao texto ou parte dele, em segundo lugar, as mudanças efetuadas não são de natureza superficial (como, por exemplo, mudanças de ortografia, correções gramaticais), mas são mudanças que remetem geralmente a uma maior clareza e organização do texto ou a uma maior adequação ao tipo de texto exigido [...] (FIAD; MAYRINK-SABINSON, 1991, p. 59).

Esse resultado se deve ao trabalho desenvolvido com os alunos que insistia na visão de que escrever é "[...] um trabalho em que ele [o aluno] se constitui como autor e em que o seu texto é constituído" (p. 56), contrário à cultura escolar que determinaria a "higienização" do texto "[...] em seus aspectos gramaticais e ortográficos, limitando-se 
a 'correções'." (GERALDI, 2002, p. 74). Nessa perspectiva, destacamos as contribuições de Ruiz (2001, 2010), que analisa o trabalho do professor como corretor do texto do aluno e os reflexos da correção na segunda versão produzida pelo aluno (mais especificamente em seu último livro). Sobre as modificações significativas nos textos reescritos pelos alunos, Fiad e Mayrink-Sabinson (1991) registram que a preocupação com maior clareza e organização manifesta-se através da substituição de expressões ou construções, inclusão ou supressão de elementos.

Alguns trabalhos (GRILLO, 1995; ALMEIDA, 2001) debruçam-se sobre a questão da reescrita ou buscam formas de viabilizá-la em sala de aula, analisando o texto escrito pelo aluno, normalmente a segunda versão, e os reflexos da orientação proposta pelo professor, procurando construir alternativas viáveis e produtivas para o trabalho pedagógico. Nessa linha, aparecem a refacção pelo próprio autor, a reescrita individual a partir da correção do texto do aluno pelo docente, a reescrita coletiva, em pares, em trios.

Contemporaneamente, o processo de retextualização vem inspirando pesquisadores a (re)analisar a reescrita, embora os conceitos mobilizados em cada estudo possam ter bases teóricas bastante diferenciadas. A título de exemplo, citamos o trabalho de Marquesi (2011), que estabelece as metarregras de Charolles (1998 apud MARCHESI, 2011) e a categorização de referentes e o uso de expressões consonantes com o contexto de produção do texto como fundamentos para o processo de reescrita. Marquesi (2011) apresenta uma sugestão de trabalho de retextualização em sala de aula, da escrita para a escrita, envolvendo quatro etapas: a leitura e a compreensão do texto a ser retextualizado, a tomada de decisão de aspectos que deverão ser reformulados, a definição do "tom" pessoal que será dado ao texto e a reescrita propriamente dita. Nessa proposta de trabalho, a autora apresenta um texto "insuficiente", produzido por um aluno de Ensino Fundamental, que foi reescrito por um discente de Ensino Médio. Logo, no processo de retextualização proposto pela pesquisadora, há uma mudança explícita de autoria.

Já nos trabalhos de Cavalcanti (2012), retextualização é a passagem de um gênero para outro. Escrever a notícia que possa ter dado origem a um artigo de opinião é o exemplo utilizado pela autora para esclarecer sua proposta. Nesse caso, o aluno só produzirá o primeiro. 
Ao pesquisar diferentes concepções de retextualização, Ribeiro (2016) conclui: “[...] o conceito de retextualização não é ponto pacífico nas teorias. [...] A reescrita, às vezes, parece sinônimo de retextualização.”. A propósito, na proposta de Marcuschi (2001), quando há a passagem de um texto oral para a "sua" escrita, o próprio autor afirma que retextualizar pode ser entendido como reescrever. Nas suas palavras:

Igualmente poderíamos usar as expressões refacção e reescrita, como fazem Raquel S. Fiad e Maria Laura Mayrink-Sabinson (1991) e Maria Bernadete Abaurre et alii (1995), que observam aspectos relativos às mudanças de um texto no seu interior (uma escrita para outra, reescrevendo o mesmo texto) sem envolver as variáveis que incidem no caso da retextualização como tratada neste estudo, preocupado essencialmente com a passagem da fala para a escrita. (MARCUSCHI, 2001, p. 46).

Essas explicitações nos fazem perceber que o termo "retextualização" tem sido utilizado com significações diferenciadas, aceitando variações metodológicas também muito variadas. Grosso modo, é possível concluir que refacção, reescrita, retextualização são termos usados atualmente em referência à etapa essencial de assumir a posição de leitor (de seu texto ou de outro), avaliando quais modificações são necessárias, o que é preciso substituir, suprimir, incluir etc., para que o texto "[...] atinja seus objetivos junto aos leitores a que se destina." (GERALDI, 2002, p. 76).

No caso específico da nossa pesquisa, utilizaremos o termo "reescrita" para designar o processo de um mesmo autor reler o seu texto e buscar trabalhá-lo, operando as modificações que considerar importantes, para que o produto resultante consiga atingir os objetivos definidos previamente.

\section{Algumas considerações sobre dialogismo, conforme o Círculo de Bakhtin}

A concepção de dialogismo é fundamental nos estudos desenvolvidos pelo Círculo de Bakhtin $(1986,2003)$ e parte do pressuposto de que a língua precisa ser estudada no processo de interação verbal (BAKHTIN/VOLOCHINOV, 1986). Os estudiosos russos preconizam:

A verdadeira substância da língua não é constituída por um sistema abstrato de formas lingüísticas nem pela enunciação monológica 
isolada, nem pelo ato psicofisiológico de sua produção, mas pelo fenômeno social da interação verbal, realizada através da enunciação ou das enunciações. A interação verbal constitui assim a realidade fundamental da língua. (1986, p. 123).

A interação verbal, para esses autores, não está restrita à comunicação em voz alta de pessoas colocadas face a face, ou àquilo que comumente chamamos de diálogo. Como diz Faraco (2009), há uma grande identificação do pensamento do Círculo com a “[...] metáfora do diálogo. E isso a tal ponto que já se tornou habitual e generalizado designar esse pensamento pelo termo dialogismo" (p. 60). Contudo, não interessa aos membros do Círculo o estudo da forma-diálogo como tal, ou seja, não constitui objeto de suas preocupações observar a maneira como se dá a troca de turnos entre participantes, nem desenvolver um estudo de práticas conversacionais de um determinado grupo. Nas palavras de Faraco (2009, p. 61), “[...] o Círculo de Bakhtin se ocupa não com o diálogo em si, mas com o que ocorre nele, isto é, com o complexo de forças que nele atua e condiciona a forma e as significações do que é dito ali”. É por isso que, para o Círculo, não há relações dialógicas na língua enquanto objeto da linguística que "por si mesmas carecem de momento dialógico" (BAKHTIN, 2005, p. 183). Elas se tornarão dialógicas quando situadas no campo do discurso, como parte integrante de todo enunciado produzido na interação social, um complexo de relações entre pessoas socialmente organizadas. Assim, há um diálogo, em sentido amplo, intrínseco e inexorável que se estabelece entre um autor e um ouvinte (ambos ativos e cambiáveis nas suas posições), e o enunciado produzido representa um momento (concluído) desse encontro, é o produto compartilhado entre os participantes da interação.

Embora possa parecer simples, o princípio do dialogismo, arquitetado pelo Círculo, é extremamente requintado, porque envolve tanto uma dimensão social quanto aquela que se pode chamar de constitutiva, inerente ao próprio dizer. Refere-se ao fato de o leitor/ouvinte já estar nas palavras do enunciador: ao falar (ou escrever), o sujeito sempre considera as futuras réplicas do seu interlocutor, o que garante que o outro, a quem o discurso se dirige, já esteja nas próprias palavras do autor.

Há ainda uma outra forma de analisar esse aspecto constitutivo do dialogismo e é anterior ao próprio ato de fala. Trata-se de conceber a minha palavra como assimilação de palavras alheias, portanto, de palavras de outros. As palavras que são 
próprias do sujeito na produção do enunciado já foram de outro(s). Ninguém é um Adão bíblico, "[...] o primeiro falante, o primeiro a ter violado o eterno silêncio do universo" (BAKHTIN, 2003, p. 272). Ao nascer, cada sujeito encontra milhares de enunciados já dados, já construídos. O sujeito vai-se constituindo discursivamente, assimilando vozes sociais, e o processo de transformação do enunciado dos outros em seu é que garantirá sua participação na vida de uma comunidade. Conforme Faraco $(2009$, p. 84),

É no interior do complexo caldo da heteroglossia e de sua dialogização que nasce e se constitui o sujeito. A realidade linguística se apresenta para ele primordialmente como um mundo de vozes sociais em múltiplas relações dialógicas - relações de aceitação e recusa, de convergência e divergência, de harmonia e de conflitos, de intersecções e hibridizações.

O dialogismo bakhtiniano, dessa forma, é tanto "externo", porque envolve sujeitos falantes e "todo falante é por si mesmo um respondente em maior ou menor grau" (BAKHTIN, 2003, p. 272), já que o caráter responsivo ativo dos enunciados exige tomá-los como réplicas a outros dizeres, quanto “interno", já que cada enunciado pressupõe a existência de um outro, esteja ele amalgamado nas palavras (assimiladas) do autor, esteja no ouvinte pressuposto a quem essas palavras se dirigem.

Logo, a alteridade bakhtiniana é eminentemente discursiva e constitutiva, o outro já está no que se enuncia, pois se instituiu no dizer do autor da enunciação. Como resume Bakhtin, cada palavra procede de alguém e também se dirige a alguém, “[...] é uma espécie de ponte lançada entre mim e os outros" (BAKHTIN, 1986, p. 113).

Dessa forma, para o Círculo de Bakhtin, todo "enunciado tem autor" (2003, p. 301). Essa ideia é plenamente coerente com a visão de sujeito bakhtiniano: um ser único, singular, mas pleno de vozes sociais, cuja unicidade ou singularidade é forçosamente obrigatória. Como assevera Bakhtin (2003, p. 190), não há “álibi” para a existência, criando em cada sujeito uma obrigatória responsabilidade sobre cada ato realizado no justo momento de sua realização.

O Círculo preconiza, ainda, a ordem metodológica para o estudo da língua:

1. As formas e os tipos de interação verbal em ligação com as condições concretas em que se realiza.

2. As formas das distintas enunciações, dos atos de fala isolados, em ligação estreita com a interação de que constituem os elementos, isto 
é, as categorias de atos de fala na vida e na criação ideológica que se prestam a uma determinação pela interação verbal.

3. A partir daí, exame das formas da língua na sua interpretação linguística habitual. (BAKHTIN/VOLOCHINOV, 1986, p. 124)

O ponto de partida dessa proposta está na impossibilidade de desvincular a linguagem das atividades humanas, pois, como afirma Bakhtin (1999, p. 185), “[...] quando cortamos o enunciado do solo real que o nutre, perdemos a chave tanto de sua forma quanto de seu conteúdo - tudo o que nos resta é uma casca linguística abstrata ou um esquema semântico igualmente abstrato".

Esse percurso metodológico aponta, então, para a necessidade de análise de aspectos mais gerais (jamais abstratos!) em direção a aspectos mais específicos, ou seja, das condições em que se realiza o gênero, de sua esfera de produção e circulação, para o enunciado concreto e, finalmente, para as formas da língua.

Vale registrar que os pressupostos aqui apresentados serão fundamentais tanto para balizar um caminho metodológico para a análise quanto para compreender o que dizem os alunos nas duas versões dos seus textos, tendo como referência a distância de tempo entre elas. Passamos agora à descrição da experiência realizada, bem como à análise das produções discentes.

\section{A pesquisa}

Esta investigação é de abordagem essencialmente qualitativa (LÜDKE; ANDRÉ, 1986) e, por isso, distancia-se da perspectiva de objetividade, neutralidade e cientificidade das pesquisas de natureza quantitativa, advindas da escola positivista. Insere-se nos princípios da pesquisa-ação, segundo pressupostos de Thiollent (2007). Para esse autor:

[...] a pesquisa-ação é um tipo de pesquisa social com base empírica que é concebida e realizada em estreita associação como uma ação ou com a resolução de um problema coletivo e no qual os pesquisadores e os participantes representativos da situação ou do problema estão envolvidos de modo cooperativo ou participativo. (p. 16)

Trata-se de pesquisa com forte interação dos atores implicados em uma ação coletiva. Por isso, as informações são interpretadas de forma participativa e 
colaborativa. Para distingui-la de outros tipos de pesquisa, o autor reafirma o fato de que há necessidade de "[...] ação por parte das pessoas ou grupos implicados no problema sob observação" (p. 17). Assevera que não pode ser uma ação trivial, ao contrário, precisa ser problemática, merecendo investigação para ser elaborada e conduzida. Nessa perspectiva, a pesquisa-ação não se torna sinônimo de ativismo, porque "[...] com ela é necessário produzir conhecimentos, adquirir experiência, contribuir para a discussão ou fazer avançar o debate acerca das questões abordadas" (THIOLLENT, 2007, p. 24).

A partir desse enquadramento da investigação, passamos agora a situar a ação desenvolvida de forma participativa entre universidade e escola, no âmbito do Projeto de Extensão denominado "Professor Universitário, Professor da Educação Básica, Aluno de Graduação e de Escola: um Encontro Necessário".

Em 2013, em uma escola pública estadual de Belo Horizonte, por solicitação de alunos, surgiu a necessidade de trabalharmos com o texto dissertativo-argumentativo em sala, visando auxiliar os discentes a enfrentar o Exame Nacional do Ensino Médio (ENEM). É importante retomar a informação de que uma das autoras deste artigo foi professora da referida turma.

A solicitação foi feita pelos próprios alunos de $1^{\circ}$ ano de Educação de Jovens e Adultos do Ensino Médio noturno que, a partir do $2^{\circ}$ semestre, foram automaticamente aprovados para o $2^{\circ}$ ano. Havia na turma 37 alunos, em sua maioria, trabalhadores. As faixas etárias eram bastante diversificadas, e os discentes possuíam trajetórias escolares diferenciadas. Enquanto alguns pararam de estudar por anos, outros sofreram várias reprovações no ensino regular e foram encaminhados à EJA. Infrequência, evasão, dificuldades em leitura e em escrita e baixa autoestima eram problemas recorrentes.

Diante da necessidade trazida pelos discentes, consideramos que desenvolver um trabalho com o texto dissertativo-argumentativo poderia se constituir em uma boa oportunidade para ampliar as práticas de letramento dos alunos, inclusive porque o domínio desse gênero escolar ${ }^{4}$ é requisito para ingressar no ensino superior. Optamos,

\footnotetext{
${ }^{4}$ Consideramos o texto dissertativo-argumentativo um gênero discursivo produzido e "consumido" na esfera escolar. A nosso ver, não há a possibilidade de tratá-lo como uma "tipologia de texto", considerando a prerrogativa bakhtiniana de que todo enunciado é sempre produzido em um gênero. Não desconsideramos, no entanto, os achados de pesquisas sobre "tipologias textuais" ou "sequências tipológicas", como formas constitutivas de diferentes gêneros. Sobre relações entre tipologias/sequências e gêneros, em língua materna, Marcuschi (2002) é uma referência importante.
} 
então, por apresentar aos alunos uma proposta de escrita utilizada como Exame Nacional no ano de 2010, diretamente relacionada à sua vida de estudante trabalhador. A Proposta de Redação do ENEM 2010 solicitava ao estudante que, com base na leitura dos textos motivadores e nos conhecimentos adquiridos ao longo de sua formação, redigisse um texto dissertativo-argumentativo em norma culta da língua portuguesa sobre o tema "O trabalho na construção da dignidade humana".

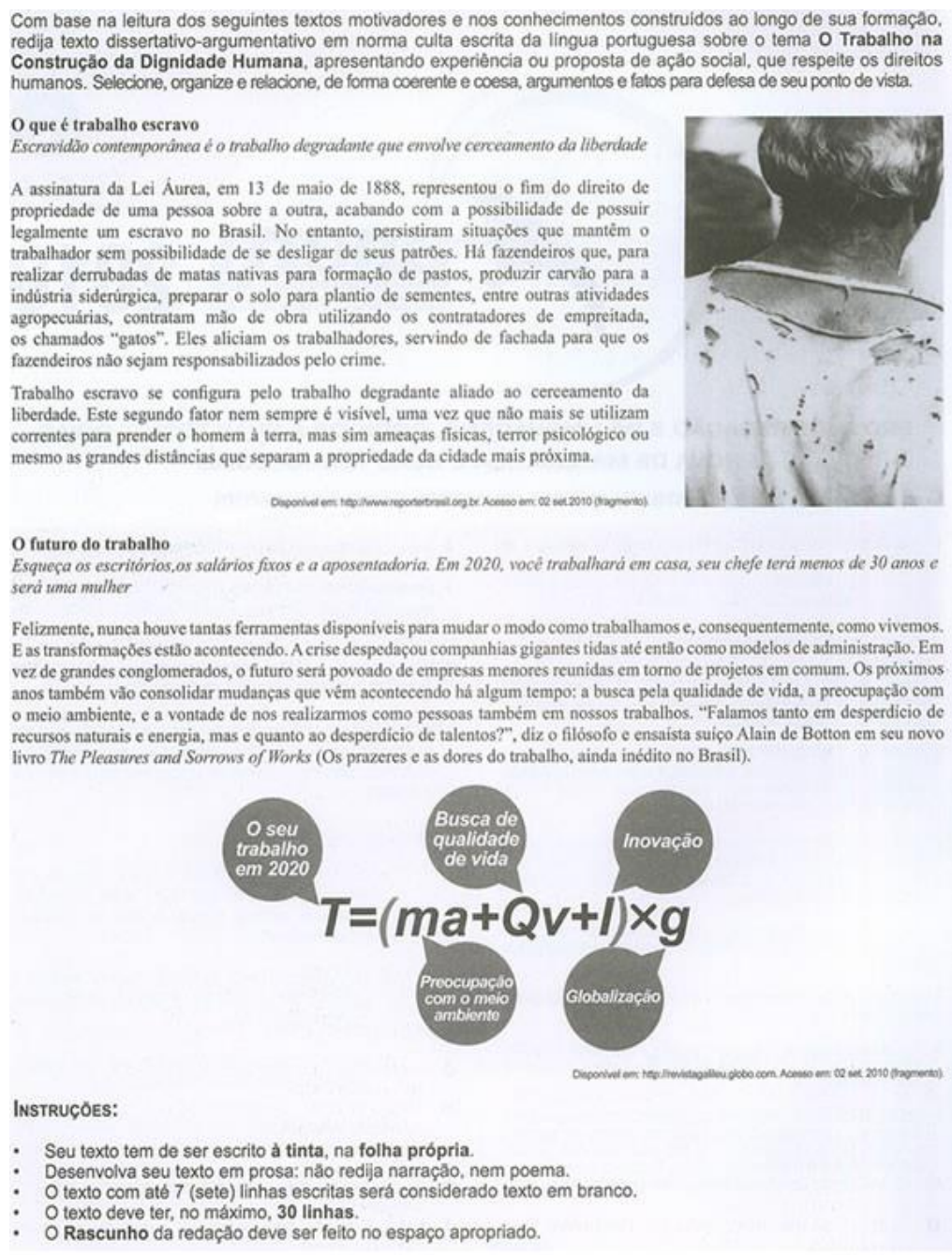

Figura 1 - Proposta de Redação do ENEM 2010

Optamos por um projeto de ensino que pudesse abarcar a integração dos eixos de leitura, escrita, análise linguística e determinar a escrita como ponto de partida e de chegada de todo o processo.

A primeira versão do texto, sem os alunos terem muitos conhecimentos sobre o gênero, foi produzida no mês de março. Um diagnóstico claro dos problemas dos textos 
produzidos foi o desencadeador do trabalho pedagógico. A análise realizada revelou problemas de todas as ordens, entre eles: incompreensão da proposta; fuga total ou parcial do tema; inadequação ao gênero; cópia dos textos-base; argumentos sem sustentação; utilização de linguagem informal; problemas quanto à pontuação, acentuação, paragrafação, ortografia.

Uma das dificuldades mais significativas dos educandos para a construção do texto a partir da proposta de redação do ENEM foi com relação à temática. Embora muitos estudantes fossem trabalhadores e tivessem conhecimento da situação do trabalhador urbano brasileiro das classes populares, não possuíam um conhecimento mais amplo que lhes permitisse analisar com criticidade a situação na qual se encontravam. Dessa forma, (re)produziram, nas produções e nas discussões na sala de aula, os preconceitos e as ideias do senso comum que constroem a imagem do trabalhador brasileiro. Por exemplo, grande parte dos alunos declarou, durante as aulas, trabalhar durante a infância para auxiliar no sustento da família, entretanto não concebia esse fato como um problema social, ao contrário, para os estudantes, trabalhar na infância ajudava na construção do caráter da criança. Muitos alunos não sabiam ao certo o que era escravidão e desconheciam que ainda havia trabalho escravo no Brasil.

Foram significativas, também, nas produções textuais, a cópia dos textos-base da proposta, a fuga parcial do tema e a repetição de ideias. Portanto, vimos como necessário trazer para as aulas outros textos, além dos que foram fornecidos na proposta do ENEM, que discutissem e trouxessem informações sobre o trabalho, para que a turma ampliasse seu conhecimento sobre o tema e, assim, tivesse o que dizer na reescrita.

Dentre outros textos, foi lido em sala um editorial ${ }^{5}$ que discute as formas de escravidão contemporâneas, fazendo um paralelo com a situação da época do Brasil Colônia. Foi exibido, ainda, o documentário "Telemarketing: o outro lado da linha"6 que mostra os problemas que afligem os trabalhadores desse setor. A escolha por esse documentário se deu pelo fato de alguns alunos trabalharem como operadores de

\footnotetext{
5 Texto disponível em: <http://www.cartamaior.com.br/?/Editoria/DireitosHumanos/Trabalho-escravo-noBrasil-de-hoje/5/1045>. Acesso em: 05 abr. 2013.

${ }^{6}$ Vídeos disponíveis em:

<https://www.youtube.com/watch?v=3E85yOoJsBs>. Acesso em: 05 abr. 2013.

<https://www.youtube.com/watch?v=vflwyL7Lt-4> Acesso em: 05 abr. 2013.

<https://www.youtube.com/watch?v=ij7dc4wRAeQ> Acesso em: 05 abr. 2013.
} 
telemarketing. As condições de trabalho expostas no documentário foram discutidas, e os alunos tiveram a oportunidade de também apresentar os problemas enfrentados por eles no desempenho de suas profissões.

Em seguida, houve um momento de reflexão sobre as possíveis reformas trabalhistas que melhorariam as condições do trabalhador. Além disso, foram lidos em sala os artigos da Constituição da República que recriminam o trabalho infantil e uma reportagem sobre o mesmo tema ${ }^{7}$.

Outras atividades, visando a corrigir os problemas diagnosticados, foram desenvolvidas com a turma e, ao final de um trabalho de oito meses, os alunos receberam novamente a Proposta de Redação e a sua produção inicial, esta última sem marcações no texto, sem correções explícitas da docente, nem mesmo os "bilhetes" uma correção textual-interativa, conforme Ruiz $(2001,2010)$-, a fim de reescrever o texto.

A decisão de não realizar marcações ou de não escrever um "recadinho" na primeira versão ${ }^{8}$ foi tomada visando a melhor compreender o processo de escrita dos integrantes da turma, acreditando que cada sujeito tem condições de se (re)posicionar diante dos fatos vividos e aprendidos e marcações poderiam "guiar" a reescrita, pois “[...] as mudanças são uma resposta a alguma observação feita pelo leitor (professor ou colega) ao texto ou parte dele [...]" (FIAD; MAYRINK-SABINSON, 1991, p. 59). Nesse sentido, o fato de um sujeito se deparar somente com o próprio texto, para revêlo, pode incitá-lo a tomar um percurso singular nesse trabalho, exigindo e provocando uma autonomia indispensável para um aluno que pretenda enfrentar um exame seletivo de âmbito nacional.

\section{As duas versões dos textos}

Tomaremos alguns pressupostos do Círculo de Bakhtin, vistos a partir da Linguística Aplicada, para a análise qualitativa que faremos da primeira e segunda versões dos textos de dois alunos. Por motivo de delimitação, nossa análise será

\footnotetext{
7 Texto disponível em: <http://portal.aprendiz.uol.com.br/arquivo/2012/12/26/trabalho-precocecompromete-a-saude-e-a-vida-de-criancas-e-adolescentes/>. Acesso em: 05 abr. 2013.

8 O texto "livre" de anotações realizadas pela professora constituiu a experiência ora descrita e analisada, não se caracterizando como prática constante ou exclusiva da docente em sala de aula.
} 
essencialmente temática, desconsiderando, portanto, outras dimensões da organização textual, inclusive, a de aspectos gramaticais, também trabalhadas durante os meses que antecederam a segunda versão.

Considerando a discussão bakhtiniana que apregoa a necessidade de se analisar a esfera de produção dos textos para posteriormente analisar o enunciado que se apresenta e as formas da língua e considerando, também, a amplitude de perspectivas que podem ser adotadas nesse quesito, optamos por focar nosso olhar, em primeiro lugar, para as condições de produção dos textos dos estudantes.

Os alunos deveriam se colocar na situação de um discente que está resolvendo a redação proposta pelo ENEM, disputando uma vaga em uma universidade pública. Nessa perspectiva, o texto foi produzido pelo aluno, a partir da imagem de uma banca de especialistas que avaliará o produto do trabalho de um estudante de Ensino Médio. A "Folha de Redação", na qual o texto foi produzido nas duas versões, é uma prova da proposta de simulação que envolveu todo o ato de escrita. Há, assim, no trabalho desenvolvido em sala, a ficcionalização ${ }^{9}$ do escrever (SCHNEUWLY, 2004), como se o aluno cumprisse a seguinte tarefa: "Imagine que você vai disputar uma vaga para entrar em uma universidade, através das provas do Enem. Redija a redação solicitada.”.

Dado o caráter de simulação criado, em última instância, há a solicitação de produção de uma redação escolar. E não se trata de qualquer redação, mas de um texto dissertativo-argumentativo, gênero de grande prestígio na esfera escolar, dado seu status de "exame nacional".

O texto produzido deve preencher uma superestrutura previamente definida: tema, tese, argumentos, proposta de intervenção (BRASIL, 2013). Sequências tipológicas argumentativas (MARCUSCHI, 2002) constituem esse gênero, dando voz a um sujeito-autor que deve

[...] demonstrar domínio da modalidade escrita formal da língua; compreender a proposta de redação e aplicar conceitos das várias áreas de conhecimento para desenvolver o tema, dentro dos limites estruturais do texto dissertativo-argumentativo em prosa; selecionar, relacionar, organizar e interpretar informações, fatos, opiniões e argumentos em defesa de um ponto de vista; demonstrar conhecimento dos mecanismos linguísticos necessários para a construção da argumentação; elaborar proposta de intervenção para o

\footnotetext{
${ }^{9} \mathrm{O}$ texto de Possenti e Mussalim (2013) traz contribuições significativas à questão.
} 
problema abordado, respeitando os direitos humanos. (BRASIL, 2013, p. 5).

Dadas essas circunstâncias inscritas no tempo-espaço de produção, passaremos a analisar dois textos em suas duas versões, produzidos por alunos distintos. Escolhemos as versões de discentes que produziram modificações significativas em seus textos, sob o ponto de vista da abordagem do tema, conforme já anunciamos. É fundamental que ressaltemos que as duas versões foram produzidas em sala de aula.

\section{Os textos do aluno A}

Para facilitar a análise, vamos transcrever a primeira versão, imediatamente após a imagem da redação, corrigindo alguns elementos da superfície textual, mas tentando preservar o conteúdo temático apresentado pelos alunos.

Primeira versão - Aluno A

Folha de Redação

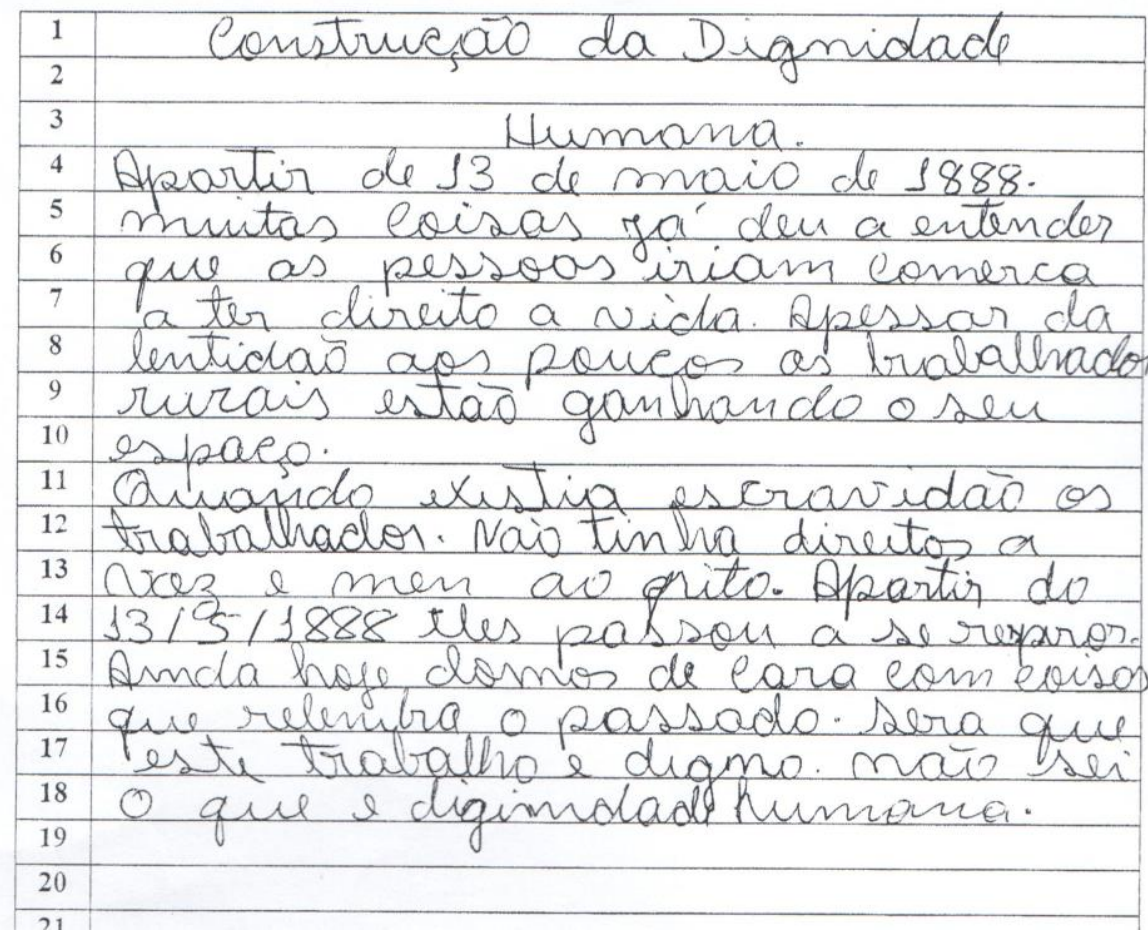

Figura 2 - Primeira versão do texto do Aluno A 


\section{Construção da dignidade humana}

A partir de 13 de maio de 1888 muitas coisas já deram a entender que as pessoas iriam começar a ter direito à vida. Apesar da lentidão, aos poucos os trabalhadores rurais estão ganhando o seu espaço.

Quando existia escravidão, os trabalhadores não tinham direitos à voz e nem ao grito. A partir de 13/5/1888, eles passaram a respirar. Ainda hoje damos de cara com coisas que relembram o passado. Será que este trabalho é digno? Não sei o que é dignidade humana.

$\mathrm{Na}$ primeira versão do texto, o autor afasta-se da ideia de existência de escravidão na atualidade. A primeira, a terceira e a quinta frases parecem ser as que mais explicitam essa ideia, inclusive pela escolha lexical realizada: "as pessoas iriam começar a ter direito à vida [a partir de 13 de maio de 1888]"; "quando existia escravidão, os trabalhadores não tinham direitos à voz e nem ao grito" e "a partir de $13 / 5 / 1888$, eles [os trabalhadores] passaram a respirar". É interessante observar que o autor não se apropriou do discurso presente no primeiro texto motivador da "Proposta de Redação", o qual diz o seguinte:

A assinatura da Lei Áurea, em 13 de maio de 1888, representou o fim do direito de propriedade de uma pessoa sobre a outra, acabando com a possibilidade de possuir legalmente um escravo no Brasil. No entanto, persistiram situações que mantêm o trabalhador sem possibilidade de se desligar de seus patrões.

A utilização de "no entanto" nesse extrato marca a relação opositiva entre "fim da escravidão" e "manutenção da escravidão". A segunda frase orienta o leitor para uma conclusão oposta e mais forte à primeira (ANSCOMBRE; DUCROT, 1977). Isso significa que a escravidão continua existindo, na opinião do articulista, mas não na visão do aluno A, apesar de ele demonstrar ter lido o extrato, ao citar explicitamente a Lei Áurea. É importante ressaltar que, na maioria dos textos, não é possível identificar a origem de um dizer e, portanto, essa última afirmativa não passa de uma suposição.

O texto do autor, então, parece revelar suas "próprias" posições, embora possamos fazer referência a Bakhtin, quando afirma que a palavra própria é assimilação da palavra do outro, ou seja, todos os nossos enunciados são plenos das palavras de um outro "[...] de um grau vário de alteridade ou de assimilabilidade, de um grau vário de aperceptibilidade e de relevância." (BAKHTIN, 2003, p. 294). E, conforme o autor, 
essas palavras do outro estão carregadas de um tom valorativo que nós “[...] assimilamos, reelaboramos e reacentuamos" (p. 295).

Dessa forma, o aluno A parece revelar uma posição individual diante das ideias de que explicitamente os textos motivadores são constituídos, mas se trata de um individual que é também social, porque há sujeitos que creem na solução do problema escravocrata no Brasil, a partir da assinatura da Lei Áurea. Sempre há um enunciado anterior, ninguém é um "Adão bíblico" (BAKHTIN, 2003, p. 300), criador de um discurso.

Logo, na visão bakhtiniana, não há indivíduo "assujeitado", já que ele "reacentua" a palavra do outro, mas sua consciência é sempre social, porque suas palavras são assimiladas de palavras já ditas. Já no texto de 1929/1986 esse ideário estava explícito:

[...] todo pensamento de caráter cognitivo materializa-se em minha consciência, em meu psiquismo, apoiando-se no sistema ideológico de conhecimento que lhe for apropriado. Nesse sentido, meu pensamento, desde a origem, pertence ao sistema ideológico e é subordinado a suas leis. Mas, ao mesmo tempo, ele também pertence a um outro sistema único, e igualmente possuidor de suas próprias leis específicas, o sistema do meu psiquismo. O caráter único desse sistema não é determinado somente pela unicidade de meu organismo biológico, mas pela totalidade das condições vitais e sociais em que esse organismo se encontra colocado. (BAKHTIN/VOLOCHINOV, 1986, p. 59).

Voltando ao texto, o aluno A, apesar de referir-se ao desaparecimento do sistema escravocrata a partir de 13 de maio de 1888, apresenta problemas na esfera do trabalho na atualidade, especialmente relacionados aos trabalhadores rurais (frase dois) e à dignidade do trabalho (últimas frases). No entanto, a ausência de argumentação que sustente o que foi apresentado impede relações mais amplas no processo de compreensão.

A pergunta formulada na penúltima frase (“Será que este trabalho é digno?”) apresenta um referente novo, "este trabalho", introduzido de forma difusa, fato que prejudica a construção de inferências por parte do leitor, no sentido de garantir a construção do sentido provavelmente pretendido pelo autor. A última frase parece ter relação direta com a anterior, algo como "se este trabalho é digno, então, não sei o que é 
dignidade humana.". Como dissemos, a ausência de elementos explícitos na superfície textual prejudica relações que possam ser estabelecidas pelo leitor.

Segunda versão - Aluno A

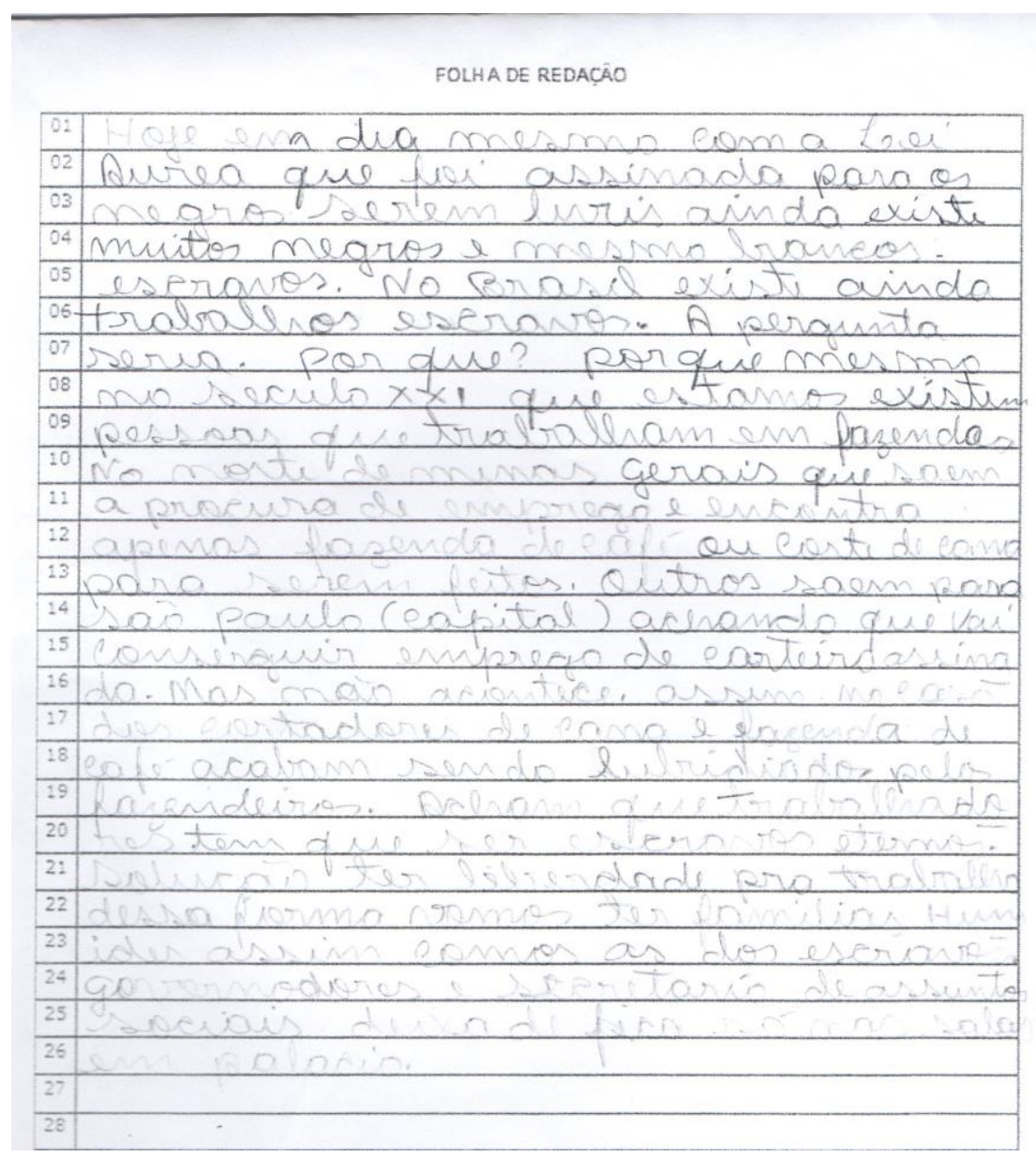

Figura 3 - Segunda versão do texto do Aluno A

Hoje em dia, mesmo com a Lei Áurea, que foi assinada para os negros serem livres, ainda existem muitos negros e mesmo brancos escravos. No Brasil existem ainda trabalhos escravos. A pergunta seria: por quê?, por que, mesmo no século XXI que estamos, existem pessoas que trabalham em fazendas no norte de Minas Gerais que saem à procura de emprego e encontram apenas fazenda de café ou corte de cana para serem feitos. Outros saem para São Paulo (capital) achando que vão conseguir emprego com carteira assinada. Mas não acontece assim. Na casa dos cortadores de cana e fazenda de café acabam sendo ludibriados pelos fazendeiros. Acham que trabalhadores têm que ser escravos eternos. Solução: ter liberdade para trabalho, dessa forma vamos ter famílias unidas, assim como as dos escravos. Governadores e Secretaria de assuntos sociais deixarem de ficar só nas salas de palácios.

Sob o ponto de vista temático, estamos diante de um aluno que modifica, neste segundo texto, a tese, a posição ideológica apresentada na primeira versão. Se, no 
anterior, a tese era o desaparecimento da escravidão no Brasil, a partir da assinatura da Lei Áurea, a tese agora é a da existência desse sistema, apesar de ter ocorrido a assinatura da referida Lei. Provavelmente, a leitura dos vários textos propostos ao longo dos oito meses de trabalho antes da escrita da segunda versão tenha feito o autor reavaliar sua posição.

Também não se pode ignorar o fato de a "Proposta de Redação" trazer um excerto que caminha nessa direção, conforme apontamos anteriormente. Como houve um trabalho significativo com a turma no sentido de melhor ler (compreender/interpretar) a Proposta recebida, construindo a "imagem" de qual o esperado pela banca de correção do texto, é possível que a adesão às ideias apresentadas na Proposta seja uma forma de dizer o que o outro quer ouvir, não necessariamente o que o autor pensa ou gostaria de dizer.

Nesse sentido, Bakhtin (2003), ao definir que cada enunciado “[...] é um elo na cadeia da comunicação discursiva" (p. 299), afirma claramente que esse enunciado não está ligado apenas aos elos precedentes, mas também aos subsequentes da comunicação discursiva, questão já apresentada por nós em seção anterior deste trabalho. Assim, “[...] o enunciado se constrói levando em conta as atitudes responsivas, em prol das quais ele, em essência, é criado.” (BAKHTIN, 2003, p. 301). Ora, estando em situação de simulação de concorrência a uma vaga em uma instituição de ensino superior, a adesão às palavras desse "outro" (avaliador do texto) pode ser fundamental para a "nota" obtida, a resposta esperada. Ainda Bakhtin (2003, p. 301): “O papel dos outros, para quem se constrói o enunciado, é excepcionalmente grande [...]”. Portanto, o texto do aluno A é produto não só do "enunciado-origem", a Proposta de Redação, mas também da imagem de um "outro-corretor", sendo este último o que define a resposta (em forma de nota-avaliativa) que será atribuída ao produto.

Obviamente, o texto dialoga também com outros tantos discursos, com a "perda das aspas" (BAKHTIN, 2003, p. 402), cuja origem é impossível determinar. Ademais, se analisarmos os textos trabalhados durante os oito meses de intervalo entre a primeira e a segunda versão, perceberemos ecos - palavra utilizada por Bakhtin em seu texto sobre gêneros do discurso - de suas palavras no que foi produzido pelo aluno A. Ao afirmar que "ainda existem negros e mesmo brancos escravos", pode estar havendo 
menção ao texto do Anexo I na seguinte afirmação: "Na escravidão contemporânea, não faz diferença se a pessoa é negra, amarela ou branca.”.

Outra passagem que pode estar se referindo a aspectos apresentados pela Proposta de Redação é a exemplificação da escravidão que acontece nas "fazendas". O texto motivador traz o seguinte: "Há fazendeiros que, para realizar derrubadas de matas nativas para formação de pastos, produzir carvão para a indústria siderúrgica, preparar o solo para plantio de sementes, entre outras atividades agropecuárias, contratam mão de obra utilizando os contratadores de empreitada, os chamados 'gatos"'. O estudante, no entanto, estabelece relações de escravismo citando outras atividades agropecuárias: fazendas de café ou de corte de cana-de-açúcar e localiza a problemática em dois Estados da região sudeste, Minas e São Paulo, sempre na perspectiva de trabalhadores migrantes.

Como dissemos, são ecos de outros discursos, cuja origem não é possível determinar, também porque não há uma clara demarcação de vozes em seu texto, através da utilização, por exemplo, de argumento de autoridade e/ou da presença de aspas. A menção à "Secretaria de assuntos sociais", na conclusão da segunda versão, também não tem uma referência explícita nos textos estudados, mas muito provavelmente possa ser fruto de discursos lidos pelo discente.

De qualquer forma, da primeira para a segunda versão, notamos não apenas um novo posicionamento autoral, mas também uma ampliação de conteúdo informacional, especialmente através da utilização de novas construções, estas se constituindo em argumentos para a sustentação da tese do aluno, qual seja, a de que o trabalho escravo não desapareceu do país com a assinatura da Lei Áurea. Estamos diante de um novo texto, sem dúvida. 


\section{Os textos do aluno B}

Primeira versão - Aluno B

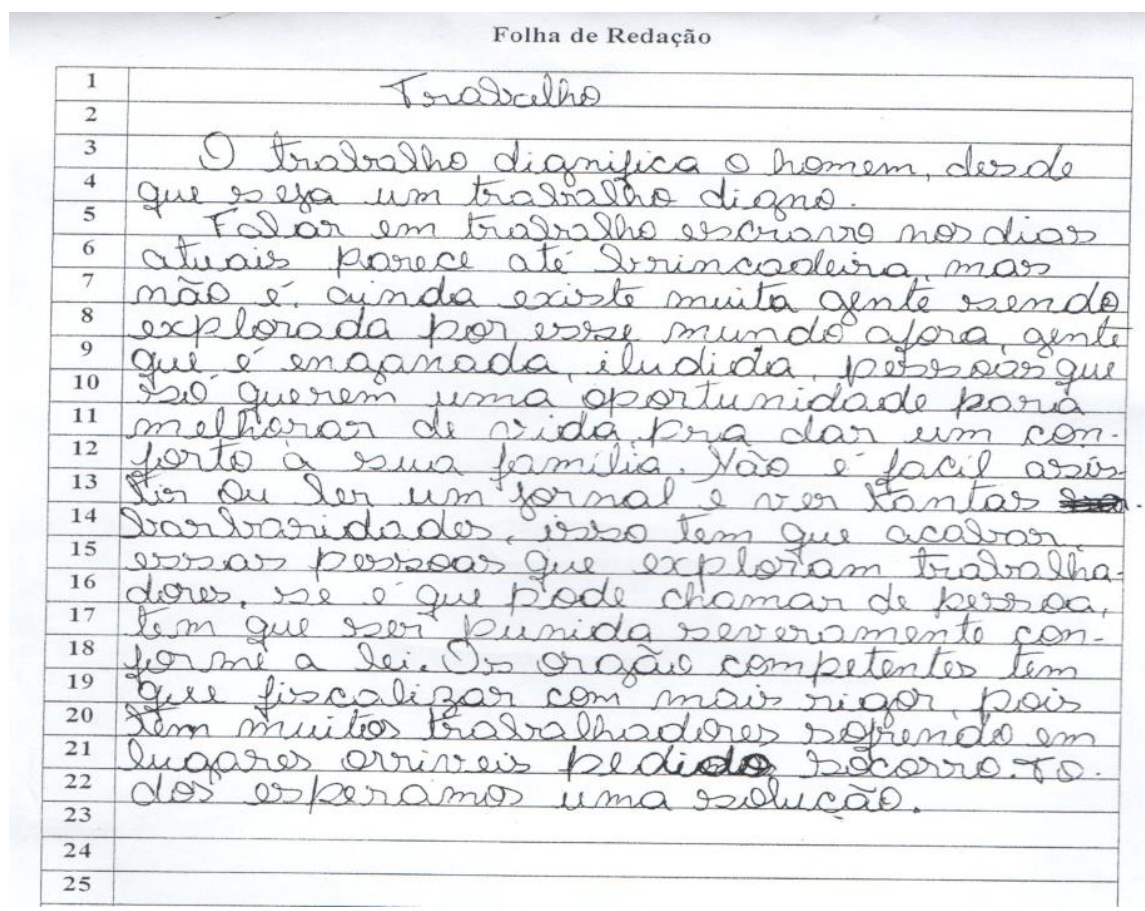

Figura 4 - Primeira versão do texto do Aluno B

\section{Trabalho}

O trabalho dignifica o homem, desde que seja um trabalho digno.

Falar em trabalho escravo nos dias atuais parece até brincadeira, mas não é, ainda existe muita gente sendo explorada por esse mundo afora, gente que é enganada, iludida, pessoas que só querem uma oportunidade para melhorar de vida para dar um conforto à sua família. Não é fácil assistir ou ler um jornal e ver tantas barbaridades, isso tem que acabar. Essas pessoas que exploram trabalhadores, se é que pode chamar de pessoa, têm que ser punidas severamente, conforme a lei. Os órgãos competentes têm que fiscalizar com mais rigor, pois têm muitos trabalhadores sofrendo em lugares horríveis, pedindo socorro. Todos esperamos uma solução.

O texto do estudante B parece organizar-se a partir de três ideias básicas: a dignidade do trabalho (abertura); a existência do trabalho escravo; e a necessária punição, por parte dos órgãos competentes, dos que exploram trabalhadores. A primeira ideia aparece imediatamente articulada, na superfície textual, a um "trabalho digno". Qual seria ele? Não há explicitações que possam ajudar o leitor a responder à questão. A condicional utilizada "desde que" escancara o pressuposto da existência de trabalhos indignos, mas a frase de abertura não é mais retomada na sequência do texto e, portanto, não permite a confirmação de hipóteses construídas pelo leitor. 
Na sequência, o autor realiza generalizações extremas, perceptíveis pela seleção lexical ("muita gente”, “gente”, “pessoas”, "trabalhadores”, "lugares horríveis”). Essa utilização generalizada de substantivos, especialmente, cria um efeito de esvaziamento argumentativo, já que todos os trabalhadores parecem envolvidos na mesma situação de “escravidão".

Numa análise circunstanciada à superfície textual, não é possível localizar, na produção do aluno, ecos dos textos motivadores de forma explícita, embora duas observações possam ser importantes: (1) nem sempre é possível buscar a origem de um dizer, conforme discorremos acima e (2) a imagem que constitui o primeiro texto motivador da Proposta de Redação pode levar o leitor a construir relações entre escravismo e "sofrimento", pessoas que vivem "barbaridades" (palavra utilizada explicitamente pelo autor no seu texto). Isso significa que a seção não-verbal constitutiva do primeiro texto motivador pode estar presente nas palavras do autor.

Segunda versão - Aluno B

FOLHA DE REDAÇĀO

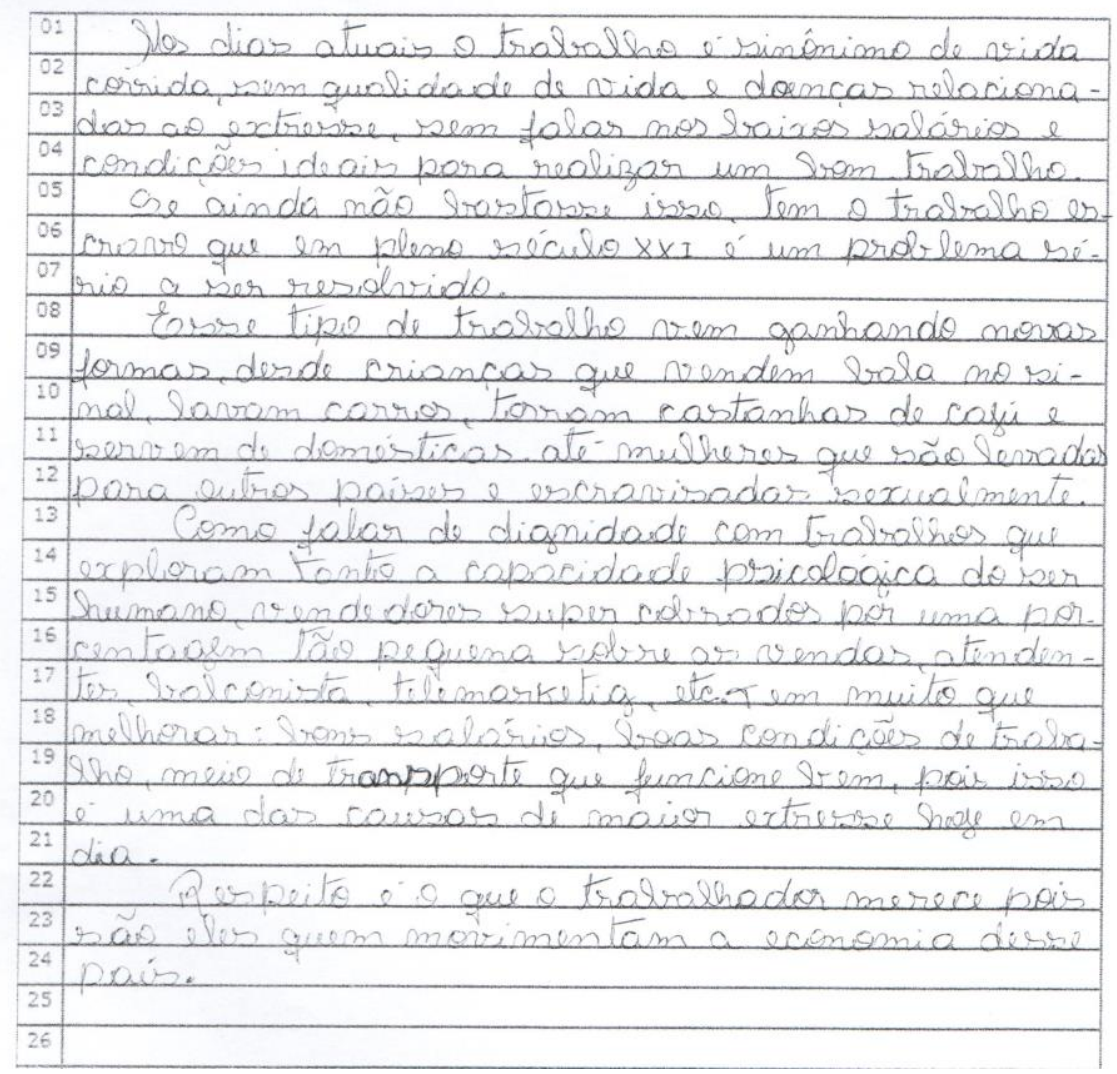

Figura 5 - Segunda versão do texto do Aluno B 
Nos dias atuais, o trabalho é sinônimo de vida corrida, sem qualidade de vida e doenças relacionadas ao estresse, sem falar nos baixos salários e condições ideais para realizar um bom trabalho.

Se ainda não bastasse isso, tem o trabalho escravo que, em pleno século XXI, é um problema sério a ser resolvido.

Esse tipo de trabalho vem ganhando novas formas, desde crianças que vendem bala no sinal, lavam carros, torram castanhas de caju e servem de domésticas, até mulheres que são levadas para outros países e escravizadas sexualmente.

Como falar de dignidade com trabalhos que exploram tanto a capacidade psicológica do ser humano, vendedores supercobrados por uma porcentagem tão pequena sobre as vendas, atendentes, balconistas, telemarketing, etc. Tem muito que melhorar: bons salários, boas condições de trabalho, meios de transporte que funcionem bem, pois isso é uma das causas de maior estresse hoje em dia.

Respeito é o que o trabalhador merece, pois são eles que movimentam a economia desse país.

A segunda versão do texto do aluno B revela que a generalização presente na primeira foi eliminada, porque o trabalho escravo é visto, agora, como mais um problema que atinge o trabalhador, lado a lado com a falta de qualidade de vida, o estresse, os baixos salários etc. A problemática da escravidão está no texto de forma bem mais específica, com exemplos concretos da sociedade brasileira, embora nenhum deles esteja presente nos textos vistos ao longo dos oito meses de estudo da temática.

A tese fundamental - as condições do trabalho no país precisam ser melhoradas - aparece articulada a várias situações vividas pelos trabalhadores, construindo um texto coerente, sob o ponto de vista da temática. Nesse sentido, não é possível afirmar que houve uma mudança de tese da primeira para a segunda versão, mas os exemplos apresentados em "desde crianças que vendem bala no sinal, lavam carros, torram castanhas de caju e servem de domésticas, até mulheres que são levadas para outros países e escravizadas sexualmente" -, demonstram conhecimento de mundo que permite ao autor hierarquizar as situações, utilizando "desde" e "até" como elementos linguístico-discursivos que estabelecem essa relação.

A palavra "telemarketing" e a expressão "capacidade psicológica" do ser humano mais facilmente são percebidas nos textos estudados durante o intervalo entre a primeira e a segunda produção. Vale lembrar que os alunos assistiram a três vídeos sobre o trabalho em telemarketing, razão, talvez, para a menção à profissão no texto do discente. 
Quanto à referência ao aspecto "psicológico" do trabalhador, tanto a Proposta de Redação - “[...] não mais se utilizam correntes para prender o homem à terra, mas sim ameaças físicas, terror psicológico [...]”- quanto um dos textos estudados - “[...] mantém-se a ordem por meio de ameaças, terror psicológico [...]”- são explícitos quanto ao "terror psicológico" impingido ao trabalhador escravo ainda nos tempos de hoje. $\mathrm{O}$ autor não utiliza "terror psicológico", mas dá uma conotação de exploração da capacidade psicológica condizente com o argumento que quer construir.

De forma geral, portanto, estamos diante de um texto mais extenso em relação ao primeiro, cujas estratégias básicas de reescrita fizeram com que as informações tenham recebido um tratamento mais articulado e relacional.

\section{Considerações finais}

A escrita, entendida como processo, prevê o trabalho de reelaboração, de reescrita. A escola, alicerçada em princípios - bastante caros à contemporaneidade - de competitividade, organiza o seu fazer de forma a privilegiar o individual, o repetitivo e o fragmentado. As tarefas são organizadas em etapas sequenciais e predeterminadas, e a produção de textos não foge a essa lógica. Escreve-se e reescreve-se - nas poucas situações em que a reescrita ocorre na escola - como etapas imediatamente sequenciais, na maioria das vezes.

Este artigo pretendeu discutir essa dinâmica. A análise de textos, a primeira versão e a respectiva reescrita, de dois alunos do primeiro ano do Ensino Médio de uma escola pública de Belo Horizonte, tendo um intervalo de tempo de oito meses entre a primeira e a segunda produção, parece apontar para a importância dessa distância temporal. A produção de um texto envolve complexos saberes, e etapas definidas de formas não tão rígidas cronologicamente podem ser fundamentais no processo, especialmente se compreendemos que a busca por novos conhecimentos e dizeres precisa de tempo. Tempo para confrontar opiniões, tempo para filiações ideológicas concordantes ou discordantes, tempo para a construção de novos argumentos, tempo para precisar "mentalmente" a imagem do interlocutor, tempo para escolher as estratégias de dizer. 
Assim, parece ser possível afirmar, a partir dos dados analisados, que nem sempre a reescrita precisa acontecer como etapa imediatamente subsequente à primeira produção. As últimas versões dos dois textos analisados propiciam discussões significativas, se considerarmos que estamos diante de sujeitos autores que não se contentaram em higienizar o que inicialmente escreveram. Ao contrário, o movimento básico foi o de construção de novos textos, porque seus autores tiveram tempo para refletir sobre a questão proposta (a dignidade do trabalho, neste caso) e tempo para trazer novos elementos para constituí-los.

Não houve, por parte dos alunos, apropriação do discurso dos textos motivadores ou dos textos estudados durante o intervalo de oito meses, embora tenhamos ecos, indícios da importância desses discursos na constituição dos novos textos. Houve novas possibilidades de constituição escrita, nascidas do contato com outros discursos, que passaram pelo processo de transformação de "palavras alheias" em "minhas palavras". (BAKHTIN, 2003, p. 292). Como bem diz Freire (2001, p. 59):

Aprender a ler e escrever se faz uma oportunidade para que mulheres e homens percebam o que realmente significa dizer a palavra: um comportamento humano que envolve ação e reflexão. Dizer a palavra, em um sentido verdadeiro, é o direito de expressar-se e expressar o mundo, de criar e recriar, de decidir, de optar.

SARTORI, Adriane Teresinha; MENDES, Lucíola Zacarias. The rewriting as a process: the advantages of a second late version. Revista do Gel, São Paulo, v. 13, n. 3, p. 130$157,2016$.

Abstract: This paper examines two versions of texts produced by students of Youth and Adult High-School Education of a public school in Belo Horizonte, confirming the rewriting as a fundamental step to the process of writing and discussing the advantages of a second late version, thus providing significant changes in the first versions delivered. The texts produced are part of an experiment carried out in the framework of an action-research (THIOLLENT, 2007) developed in a collaborative relationship between public school and higher education institution. The qualitative analysis grounded in dialogic design of Bakhtin's Circle (1986, 2003), especially focuses on the thematic aspects of texts, seeking to understand the articulation of voices performed by students. The positive results of the experiment seems to prove the importance of a significant gap between the production of versions of a same text, aiming to give time for the author to take ownership of new / other knowledge. 
Keywords: Writing. Rewriting. Time interval. Dialogism.

Submetido em: 19/05/2016.

Aceito em: 20/07/2016.

\section{Referências}

ALMEIDA, M. S. Refacção como ação pedagógica: o olhar do outro sobre o texto orienta a refacção? 2001. 151 p. Dissertação (Mestrado em Linguística Aplicada) Instituto de Estudos da Linguagem, Universidade Estadual de Campinas, Campinas, 2001.

ANSCOMBRE, J. C.; DUCROT, O. Deux mais en français? Língua, v. 43, n. 1, p. 23 40, oct. 1977.

BAKHTIN, M./VOLOCHINOV, V. Marxismo e filosofia da linguagem. Tradução de Michel Lahud e Yara Frateschi Vieira. 3. ed. São Paulo: Hucitec, 1986.

El discurso en la vida y el discurso en el arte (acerca da la poética sociológica). In: VOLOSHINOV, V. Freudismo: un bosquejo crítico. Buenos Aires-BarcelonaMéxico: Paidós, 1999. (Espacios del Saber).

BAKHTIN, M. Os gêneros do discurso. In: Estética da criação verbal. Tradução de Paulo Bezerra. São Paulo: Martins Fontes, 2003. p. 261-306.

Apontamentos de 1970-1971. In: Estética da criação verbal. Tradução de Paulo Bezerra. São Paulo: Martins Fontes, 2003. p. 367-392.

Metodologia das Ciências Humanas. In: Estética da criação verbal. Tradução de Paulo Bezerra. São Paulo: Martins Fontes, 2003. p. 393- 410.

Problemas da poética de Dostoievski. Tradução de Paulo Bezerra. 3. ed. Rio de Janeiro: Forense Universitária, 2005.

BRASIL. Ministério da Educação. Instituto Nacional de Estudos e Pesquisas Educacionais Anísio Teixeira (INEP). A redação no ENEM 2013: guia do participante. Brasília, DF, 2013.

CAVALCANTI, J. R. Professor, leitura e escrita. São Paulo: Livraria Saraiva, 2012.

FARACO, C. A. Linguagem e diálogo: as ideias do Círculo de Bakhtin. São Paulo: Parábola Editorial, 2009.

FIAD, R. S.; MAYRINK-SABINSON, M. L. T. A escrita como trabalho. In: MARTINS, M. H. (Org.). Questões de linguagem. São Paulo: Contexto, 1991. p. 5463. 
FREIRE, P. Educação como prática da liberdade. Rio de Janeiro: Paz e Terra, 2001.

GERALDI, J. W. Portos de passagem. 4. ed. São Paulo: Martins Fontes, 1997. (Texto e Linguagem).

. (Org.). O texto na sala de aula. Paraná: Assoeste, 1984.

(Org.). O texto na sala de aula. 3. ed. São Paulo: Ática, 2002.

GRILLO, S. Escrever se aprende reescrevendo: um estudo da interação professor/aluno na revisão de textos. 1995. 148 p. Dissertação (Mestrado em Linguística Aplicada) - Instituto de Estudos da Linguagem, Universidade Estadual de Campinas, Campinas, 1995.

JESUS, C. A. de. Reescrevendo o texto: a higienização da escrita. In: CHIAPPINI, L. Aprender e ensinar com textos. v. 1. São Paulo: Cortez, 1997. p. 99-117.

LÜDKE, M.; ANDRÉ, M. E. D. A. Pesquisa em educação: abordagens qualitativas. São Paulo: EPU, 1986. (Temas básicos de educação e ensino).

MARCUSCHI, L. A. Da fala para a escrita: atividades de retextualização. 3. ed. São Paulo: Cortez, 2001.

. Gêneros textuais: definição e funcionalidade. In: DIONISIO, A. P.; MACHADO, A. R.; BEZERRA, M. A. (Org.). Gêneros textuais \& ensino. Rio de Janeiro: Lucerna, 2002. p. 19-36.

MARQUESI, S. C. Escrita e reescrita de textos no ensino médio. In: ELIAS, V. M. (Org.). Ensino de Língua Portuguesa: oralidade, escrita, leitura. São Paulo: Contexto, 2011. p. 135-143.

POSSENTI, S.; MUSSALIM, F. A problemática da transposição didática do conceito de gênero do discurso: em pauta os fenômenos da "intertextualidade intergêneros" e da “ficcionalização". Revista Letras \& Letras, v. 29, n. 2, p. 1-14, 2013.

RIBEIRO, A. E. Textos multimodais: leitura e produção. São Paulo: Parábola Editorial, 2016.

RUIZ, E. Como se corrige redação na escola. Campinas: Mercado de Letras, 2001.

Como corrigir redações na escola: uma proposta textual interativa. São Paulo: Contexto, 2010.

SCHNEUWLY, B. Palavra e ficcionalização: um caminho para o ensino da linguagem oral. In: SCHNEUWLY, B.; DOLZ, J. e colaboradores. Gêneros orais e escritos na escola. ROJO, R. (Org.). Campinas: Mercado de Letras, 2004. p. 129-147. 
SILVA, L. L. M. da; ALMEIDA FERREIRA, N. S. de; MORTATTI, M. R. L. (Org.). O texto na sala de aula: um clássico sobre ensino de língua portuguesa. Campinas: Autores Associados, 2014. (Coleção formação de professores).

THIOLlENT, M. Metodologia da pesquisa-ação. 2. ed. São Paulo: Cortez, 1986. (Coleção Temas Básicos de Pesquisa-Ação). 